\title{
(6) OPEN ACCESS \\ Resuscitative endovascular balloon occlusion of the aorta (REBOA): a population based gap analysis of trauma patients in England and Wales
}

\author{
Edward Benjamin Graham Barnard, ${ }^{1,2}$ Jonathan James Morrison, 3,4 \\ Ricardo Mondoni Madureira, ${ }_{1}^{5}$ Robbie Lendrum, ${ }_{1}^{6}$ Marisol Fragoso-Iñiguez, ${ }^{7}$ \\ Antoinette Edwards, ${ }^{7}$ Fiona Lecky, ${ }^{7,8}$ Omar Bouamra, ${ }^{7}$ Thomas Lawrence, ${ }^{7}$ \\ Jan Olaf Jansen ${ }^{9,10}$
}

For numbered affiliations see end of article.

\section{Correspondence to} J 0 Jansen, Departments of Surgery and Intensive Care Medicine, Aberdeen Royal Infirmary, Aberdeen AB25 2ZN, UK; jan.jansen@nhs.net

Received 12 July 2015 Revised 25 October 2015 Accepted 28 October 2015
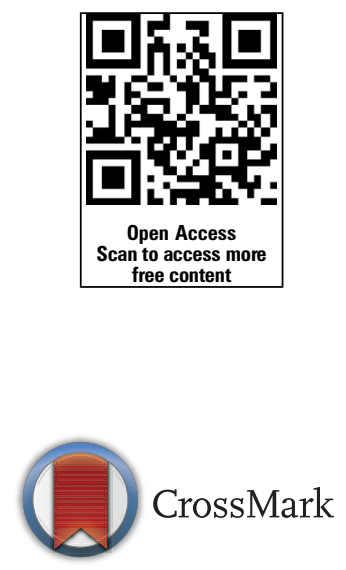

\section{INTRODUCTION}

Haemorrhage is the leading cause of potentially preventable death following traumatic injury. ${ }^{1-7}$ Non-compressible torso haemorrhage (NCTH), defined as vascular disruption to the axial torso vessels, solid organs, pulmonary parenchyma or the bony pelvis, accompanied by shock, ${ }^{8}$ has a mortality of approximately $45 \% .^{9} \quad 10$ A significant

\section{Key messages}

What is already known on this subject?

- Haemorrhage is the leading cause of potentially survivable death in trauma.

- Resuscitative endovascular occlusion of the aorta (REBOA) has been shown in large animal models to improve survival in non-compressible torso haemorrhage but early clinical data are equivocal.

\section{What might this study adds?}

- The number of patients in England and Wales in whom REBOA may be utilised is small, but they have a mortality of $32 \%$.

- The highest density of potential REBOA patients is seen at major trauma centres.

proportion of these deaths occur before the opportunity for definitive haemorrhage control in an operating theatre or interventional radiology suite. $^{2}{ }^{10}$ There is therefore a need for a haemorrhage control adjunct, to achieve temporary cessation of bleeding, until definitive haemostasis can be achieved.

Resuscitative endovascular balloon occlusion of the aorta (REBOA) involves the temporary occlusion of the aorta, using a percutaneously deployed intravascular balloon, usually inserted via the femoral artery. REBOA has demonstrated potential application in large animal models and several human studies. In animal models of NCTH, REBOA has been shown to improve survival,,${ }^{11} 12$ increase blood pressure (BP), ${ }^{11}{ }^{13}{ }^{14}$ brain oxygenation and carotid arterial blood flow. ${ }^{14}{ }^{15}$ REBOA has also been demonstrated to be superior to haemostatic gauze in the control of pelvic haemorrhage. ${ }^{12}$ In two human case series, of 13 and 6 patients, survival from presumed lethal NCTH was shown to be between $46 \%$ and $67 \% .^{16}{ }^{17}$ However, more recent publication of a large, retrospective, propensity score matched data study from the Japan Trauma Data bank suggested that the use of REBOA in blunt abdominal trauma is associated with increased mortality (OR of survival $0.3,95 \%$ CI 0.23 to 0.40$){ }^{18}$ The decision to use REBOA in this study was based on the physicians' clinical decision making (ie, not according to a clinical practice 
guideline), and the authors state that the results may reflect REBOA being used in a 'last ditch' effort in otherwise unsalvageable patients. However, these data highlight the need to better evaluate the potential benefit or harm of REBOA before widespread clinical implementation.

The decision to use REBOA should be part of a robust clinical governance framework in order to ensure both high quality patient care and the ability to make valid observations and/or comparisons about the effectiveness of this novel therapy. Part of this framework concerns training but to date there is no consensus on the training requirement for REBOA. ${ }^{19} \mathrm{~A}$ number of centres have described their own training packages, ${ }^{20-22}$ with evidence that as little as 2 days of training, ${ }^{21}$ or didactic instruction followed by six REBOA insertions in a virtual reality suite, is adequate. ${ }^{22}$ Some of the skills required for REBOA deployment (vascular access, endovascular wire placement, balloon placement) may be translatable from existing trauma centre experience (among emergency physicians, intensivists, vascular surgeons and interventional radiologists) but the importance of dedicated training within robust governance cannot be emphasised enough.

A 2015 review of the potential use of REBOA in exsanguinating haemorrhage suggests that this new technique should be 'evaluated rigorously' before universal acceptance. ${ }^{23}$ This paper provides an algorithm to guide management of these patients, in which REBOA may be considered, as local expertise permits, but that emergency department thoracotomy and aortic cross clamp is preferred. Biffl et al's $\mathrm{s}^{23}$ recommendation in pelvic haemorrhage however is that the use of REBOA should be the preferred management option, particularly if there is a likely delay to definitive haemostasis. There is a paucity of controlled human data which quantifies any benefit or potential harm of REBOA and a comparison with established medical management $-\mathrm{a}$ randomised controlled trial is therefore urgently required.

In planning future REBOA studies it will be important to know the proportion of patients who have indications (and no contraindications) to this intervention-this number is currently unknown. Therefore, we have conducted a gap analysis, using the Trauma Audit and Research Network's (TARN-NHS England and Wales trauma database) registry, and anatomical injury scores, to identify the number of patients in whom REBOA may have reasonably been utilised. The primary aim was to identify the number of patients with an anatomical injury and admission physiology that was theoretically amenable to REBOA. The secondary aims included an analysis of injury patterns, mortality, resources required for patient management and the type of trauma hospital at which patients were first managed. This study will be used to inform the implementation and further study of aortic balloon occlusion in patients with traumatic haemorrhage.

\section{METHODS}

This was a retrospective analysis of the cohort of major trauma patients presenting to hospitals in England and Wales between 1 January 2012 and 31 December 2013. Data were obtained from TARN. TARN was established 25 years ago and now holds the largest trauma registry in Europe. It is the national clinical audit for trauma care, which collects data on patients with moderate to major injuries from all trauma receiving hospitals in England, Wales and the Republic of Ireland, with participation from some hospitals across other parts of Europe. The information is submitted electronically by each hospital to TARN via a web based data collection system and follows the patient pathway from prehospital to discharge, including key observations, interventions and outcome at 30 days. Inclusion criteria were all adults ( $\geq 16$ years old) with a known outcome who met the TARN inclusion criteria (admission to hospital 3 days or longer, intensive or high dependency care or transfer for further specialist care). Patients with an Abbreviated Injury Scale (AIS) score of 6 (an anatomically unsurvivable injury) in any body region were excluded. During the study timeframe, $98 \%$ of hospitals across England and Wales were submitting data to TARN.

Two zones of aortic occlusion have been described: zone 1 (Z1) occlusion-between the left subclavian artery and the coeliac artery (for the management of exsanguinating abdominal haemorrhage); zone 3 (Z3) occlusion-between the caudal renal artery and the aortic bifurcation (for the management of exsanguinating pelvic or lower limb haemorrhage). There is no published consensus on the indications or contraindications for the use of REBOA. We therefore utilised methodology from a previous military combat study, aimed at identifying patients in whom REBOA may have been utilised. ${ }^{24}$ This paper suggested that Z1 occlusion was indicated in abdominal haemorrhage (high grade solid organ injury, mesenteric disruption or injury to a named vessel proximal to the aortic bifurcation) and that $\mathrm{Z} 3$ occlusion was indicated for pelvic and/or groin haemorrhage (pelvic fracture with ring disruption, traumatic amputation at or near the hip or injury to a named vessel proximal to the femoral segments). ${ }^{24}$ The AIS codes for these injuries were used to identify those with an indication for REBOA (all zones, Z1 and Z3) (table 1).

Contraindications were identified in the same way, and in general included non-compressible haemorrhage proximal to the proposed zone of occlusion: thoracic aortic disruption and arterial injury within the superior mediastinum, axilla and face (table 1). Those patients with both an indication and a contraindication were placed in the contraindication group. Physiological indication for REBOA was a hospital arrival systolic BP (SBP) $<90 \mathrm{~mm} \mathrm{Hg}$.

In order to differentiate deaths due to haemostatic failure (as opposed to neurological or multiorgan failure), fatalities were dichotomised into early deaths (within $12 \mathrm{~h}$ of hospital arrival) and late deaths (more than $12 \mathrm{~h}$ after hospital arrival). Although it is acknowledged that severe neurological injury may result in early death, those with a head AIS score of 6 (anatomically unsurvivable traumatic brain injury) were excluded.

The Trauma Network in England became operational in April 2012. There are therefore 3 months in this study period, from January 2012, in which hospitals were not officially designated as major trauma centres (MTCs) or trauma units (TU). In recognition that MTCs were already planning for their new trauma status at the start of this study, the patients they received in the

Table 1 Anatomical indications and contraindications to REBOA

\begin{tabular}{|c|c|c|}
\hline \multicolumn{2}{|l|}{ Indications } & \multirow[b]{2}{*}{ Contraindications } \\
\hline Zone 1 & Zone 3 & \\
\hline High grade (AIS $\geq 3$ ) injury & High grade (AIS $\geq 3$ ) injury & NCTH in \\
\hline Liver/kidney/spleen & $\begin{array}{l}\text { Pelvic fracture with ring } \\
\text { disruption }\end{array}$ & $\begin{array}{l}\text { Superior } \\
\text { mediastinum }\end{array}$ \\
\hline Mesenteric disruption & Named pelvic vessel injury & Axilla \\
\hline $\begin{array}{l}\text { Named abdominal } \\
\text { vessel injury }\end{array}$ & $\begin{array}{l}\text { Traumatic amputation } \\
\text { at/near hip }\end{array}$ & Face or neck \\
\hline
\end{tabular}


first 3 months of this study were included in the MTC group. Patients received at hospitals who were to become TUs in April 2012 were included in the TU group. To date, Wales does not have a Trauma Network, and therefore all trauma patients in Wales were included in the TU group.

\section{Data analysis}

Basic demographics, and admission physiology and injury data are reported as number $(\%)$, mean $(95 \% \mathrm{CI})$ or median (IQR). Continuous data were analysed using the Mann-Whitney U test, and categorical data were analysed using the $\chi^{2}$ test. All hypotheses testing were performed with SPSS V.22.0 (IBM Corp. Armonk, New York, USA). Comparisons of resource utilisation was performed by calculating OR (95\% CI) between groups with Prism V.6.0f (Graphpad Software Inc, La Jolla, California, USA).

\section{RESULTS}

During 2012 and 2013, 72677 adult patients were included in the TARN registry: 3543 (4.9\%) patients had anatomical indications for, and no contraindications to, REBOA, and 397 $(0.55 \%)$ of these presented in shock (REBOA group, figure 1$)$. The frequency of anatomical indications in this cohort is described in table 2 .

When analysed by zone of occlusion, 201 (50.6\%) patients would have required Z1 occlusion, $161(40.6 \%)$ patients would have required $\mathrm{Z} 3$ occlusion and 35 (8.8\%) patients had independent indications for both $\mathrm{Z} 1$ and $\mathrm{Z} 3$ occlusion. For further analyses, and to maintain clinical relevance, those with indications for both $\mathrm{Z} 1$ and $\mathrm{Z} 3$ occlusion have been included in the $\mathrm{Z} 1$ subgroup, as in order to control haemorrhage in both areas, a proximal (Z1) aortic balloon would be required.

\section{Demographics}

The REBOA group consisted of $273(68.8 \%)$ male patients, with a median age of 43 (27.8 to 60.2$)$ years. More than $90 \%$

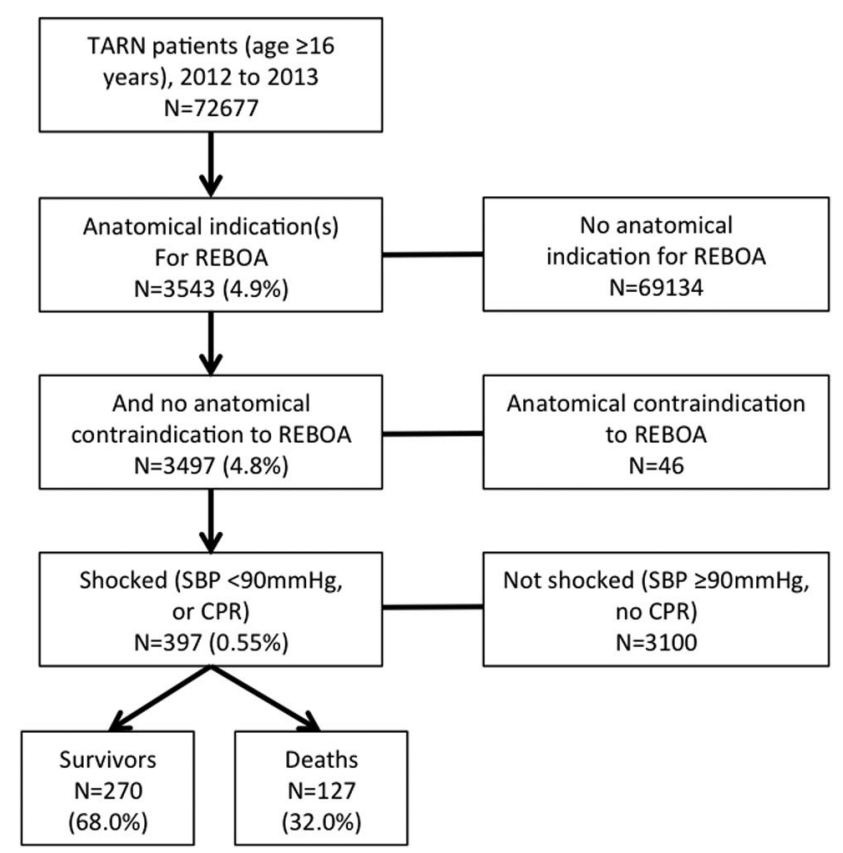

Figure 1 Study inclusion and exclusion criteria. CPR, cardiopulmonary resuscitation; REBOA, resuscitative endovascular balloon occlusion of the aorta; SBP; systolic blood pressure; TARN, Trauma Audit and Research Network. had a blunt mechanism of injury, and over half were injured in a road traffic collision (table 3 ).

Compared with the TARN patients with no indication for REBOA, the REBOA group were younger, more likely to be male, more likely to have a penetrating mechanism of injury (9.3\% (95\% CI 6.5 to 12.2 ) vs $2.8 \%$ (2.7 to 2.9$)$ ), more likely to have been injured in a road traffic collision $(54.7 \%$ (49.8 to 59.6) vs 19.1 (18.8 to 19.4$)$ ), less likely to have been injured in a fall under $2 \mathrm{~m}$ (9.6\% (6.7 to 12.5$)$ vs $56.9 \%$ (56.5 to 57.3$)$ ), have a higher Injury Severity Score (ISS), more likely to have had a thoracic injury $(62.0 \%$ (57.2 to 66.7$)$ vs $17.4 \%(17.1$ to 17.6)) and more likely to have an abdominal injury $(67.8 \%$ (63.2 to -72.4$)$ vs $0.8 \%(0.8$ to 0.9$)$; all $\mathrm{p}<0.001)$ (table 3$)$.

\section{Injury patterns}

The Z3 subgroup were statistically more likely to have been injured in a fall over $2 \mathrm{~m}$ than the $\mathrm{Z} 1$ subgroup (29.2\% (22.2 to 36.2 ) vs $13.1 \%$ (8.8 to 17.4$) ; \mathrm{p}<0.001)$. They were also more likely to be older $(p=0.02)$ and have a higher ISS $(p<0.01)$ (table 3). However, there were no other significant differences in demographics, mechanism of injury or admission physiology between these subgroups.

\section{Resource utilisation}

Two hundred and eighteen (54.9\%) patients in the REBOA group received a blood transfusion in the first $24 \mathrm{~h}$ from admission compared with $2634(4.0 \%)$ of those with no indication for REBOA and 3708 (5.3\%) patients in the entire cohort. The median number of units of packed red cells and fresh frozen plasma used in the REBOA group in the first $24 \mathrm{~h}$ was $6 .^{3-10}$

The REBOA group $(n=397)$ required significantly more resources than those with no indication for REBOA $(n=69$ 134). The odds of requiring a thoracotomy, laparotomy, embolisation, surgical pelvic stabilisation, activation of a trauma team, activation of a massive transfusion protocol, a blood transfusion within $24 \mathrm{~h}$ of hospital arrival and administration of tranexamic acid were all significantly higher in the REBOA group (all $\mathrm{p}<0.001$ ). The ORs produced between these two groups were high (eg, the OR for activation of a massive transfusion protocol was 41), which suggests the comparison is of limited usefulness. We therefore further compared the REBOA group (those with anatomical indications, no contraindications and haemodynamically shocked, $n=397$ ) with those with an indication for REBOA without evidence of shock $(n=3100)$. In this latter comparison, the REBOA group were still significantly more likely to require all the examined resources $(p<0.001)$ with the exception of embolisation (figure 2 ). This result indicates a group of patients which, although small in number, place a heavy resource burden on the health service.

\section{Mortality}

The overall mortality of the REBOA group was $32.0 \% \quad(n=127$ out of 397). There was no statistical mortality difference between the Z1 and Z3 subgroups (34.7\% (28.7 to 40.8) vs $28.0 \%$ (21.0 to 34.9$) ; \mathrm{p}=0.20)$.

We dichotomised the deaths into early $(\leq 12 \mathrm{~h}$ of hospital arrival, $62.2 \%)$ and late $(>12 \mathrm{~h}$ after hospital arrival, $37.8 \%)$ groups in order to better differentiate deaths due to haemorrhage (and therefore potentially amenable to REBOA). This evaluation showed that survivors had a lower ISS than all deaths $(p<0.001)$, and that there was no difference in ISS between early and late deaths $(p=0.90)$. Severe traumatic brain injury (TBI) was more likely in deaths than survivors (43.3\% (34.7 to $51.5)$ vs $13.7 \%(9.6$ to 17.8$) ; \mathrm{p}<0.001)$ but there was no 
Table 2 Frequency of anatomical indications for REBOA in this cohort, with and without the presence of haemorrhagic shock

\begin{tabular}{|c|c|c|c|c|c|c|}
\hline \multirow[b]{2}{*}{ AIS $\geq 3$ injury to } & \multicolumn{3}{|c|}{ Zone 1 indication $(n=236)$} & \multicolumn{3}{|c|}{ Zone 3 indication $(n=196)^{*}$} \\
\hline & $\begin{array}{l}\text { Liver/kidney/ } \\
\text { spleen }\end{array}$ & $\begin{array}{l}\text { Mesenteric } \\
\text { disruption }\end{array}$ & $\begin{array}{l}\text { Named vessel } \\
\text { injury }\end{array}$ & $\begin{array}{l}\text { Pelvic } \\
\text { fracture }\end{array}$ & $\begin{array}{l}\text { Named vessel } \\
\text { injury }\end{array}$ & $\begin{array}{l}\text { Amputation at } \\
\text { or near hip }\end{array}$ \\
\hline Anatomical indications for REBOA & 1530 & 58 & 111 & 1932 & 167 & 2 \\
\hline $\begin{array}{l}\text { Anatomical indications for REBOA } \\
\text { (no contraindications and not shocked) }\end{array}$ & 1503 & 48 & 91 & 1728 & 131 & 2 \\
\hline REBOA group (n (\%)) & $218(92.4)$ & $10(4.2)$ & $16(6.8)$ & $177(90.3)$ & $29(14.8)$ & 0 \\
\hline
\end{tabular}

REBOA group, patients with an anatomical indication for REBOA, with no anatomical contraindications and with physiological evidence of hypovolaemic shock.

*Patients with both zone 1 and zone 3 anatomical indications $(n=35)$ are included in both zones' denominators.

AIS, Abbreviated Injury Scale score; REBOA, resuscitative endovascular balloon occlusion of the aorta.

difference between early and late deaths (43.0\% (32.1 to 53.9) vs $43.8 \%$ (29.8 to 57.8$) ; \mathrm{p}=1.0)$.

Early deaths were more likely than late deaths to have admission physiology consistent with traumatic cardiac arrest (TCA) (lower pulse, lower SBP, lower Glasgow Coma Scale score; $\mathrm{p}<0.001)$. In the early death group, $31(39.2 \%)$ patients had an SBP of 0 , and $28(35.4 \%)$ had a heart rate of 0 (table 4$)$.
Type of receiving hospital

The majority $(64.5 \%)$ of TARN patients were initially admitted to TUs. However, two-thirds of the REBOA group were primarily conveyed to a MTC (table 5).

This concentration of patients in whom REBOA may have been applied at MTCs is further increased by the fewer number of MTCs (32 vs 223 TUs). The mean number of REBOA

Table 3 Demographics, injury pattern and physiology on arrival to hospital for TARN patients without an indication for REBOA, those with an anatomical and physiological indication and no contraindications for REBOA, and by zone of aortic occlusion indicated

\begin{tabular}{|c|c|c|c|c|}
\hline & No indication for REBOA & $\begin{array}{l}\text { REBOA } \\
\text { (zones } 1 \text { and 3) }\end{array}$ & $\begin{array}{l}\text { REBOA } \\
\text { (zone 1) }\end{array}$ & $\begin{array}{l}\text { REBOA } \\
\text { (zone 3) }\end{array}$ \\
\hline No of patients & 69134 & 397 & 236 & 161 \\
\hline \multicolumn{5}{|l|}{ Gender (n (\%)) } \\
\hline Men & $38485(55.7)$ & $273(68.8)$ & $163(69.1)$ & $110(68.3)$ \\
\hline Women & $30649(44.3)$ & $124(31.2)$ & $73(30.9)$ & $51(31.7)$ \\
\hline ISS (median (IQR)) & $9.0(9.0-16.0)$ & $32.0(20.0-45.0)$ & $29.0(18.0-43.0)$ & $36.0(25.0-45.0)$ \\
\hline Age (years) (median (IQR)) & $62.3(44.0-80.6)$ & $43.0(27.8-60.2)$ & $40.7(27.2-57.2)$ & $48.0(29.8-65.3)$ \\
\hline \multicolumn{5}{|l|}{ Mode of injury ( $\mathrm{n}(\%))$} \\
\hline Blunt & $67211(97.2)$ & $360(90.7)$ & $215(91.1)$ & $145(90.1)$ \\
\hline Stab & $1241(1.8)$ & $35(8.8)$ & $20(8.5)$ & $15(9.3)$ \\
\hline Gunshot wound & $139(0.2)$ & $1(0.3)$ & (0) & $1(0.6)$ \\
\hline Other penetrating & $543(0.8)$ & $1(0.3)$ & $1(0.4)$ & (0) \\
\hline \multicolumn{5}{|l|}{ Mechanism of injury (n (\%)) } \\
\hline RTC & $13204(19.1)$ & $217(54.7)$ & $132(55.9)$ & $85(52.8)$ \\
\hline Fall $>2 \mathrm{~m}$ & $9491(13.7)$ & 78 (19.6) & 31 (13.1) & $47(29.2)$ \\
\hline Fall $<2 \mathrm{~m}$ & $39335(56.9)$ & $38(9.6)$ & $28(11.9)$ & $10(6.2)$ \\
\hline Shooting/stabbing & $1380(2)$ & $36(9.1)$ & $20(8.5)$ & $16(9.9)$ \\
\hline Blow(s) & $3700(5.4)$ & $21(5.3)$ & $21(8.9)$ & (0) \\
\hline Other & $2024(2.9)$ & $7(1.8)$ & $4(1.7)$ & $3(1.9)$ \\
\hline \multicolumn{5}{|c|}{ Injury pattern (AIS 3+) ( $n(\%)$ ) } \\
\hline Head & $16934(24.5)$ & $92(23.2)$ & $50(21.2)$ & $42(26.1)$ \\
\hline Thorax & $11999(17.4)$ & $246(62)$ & $160(67.8)$ & $86(53.4)$ \\
\hline Abdomen & $571(0.8)$ & $269(67.8)$ & $236(100)$ & $33(20.5)$ \\
\hline Upper limb & $1266(1.8)$ & $5(1.3)$ & $3(1.3)$ & $2(1.2)$ \\
\hline Lower limb & $20198(29.2)$ & $89(22.4)$ & $32(13.6)$ & $57(35.4)$ \\
\hline Pelvis & $0(0.0)$ & $177(44.6)$ & $34(14.4)$ & $143(88.8)$ \\
\hline Other & $762(1.1 \%)$ & $7(1.8)$ & $2(0.8)$ & $5(3.1)$ \\
\hline \multicolumn{5}{|c|}{ Admission physiology (median (IQR)) } \\
\hline $\mathrm{SBP}(\mathrm{mm} \mathrm{Hg})$ & $138(121-155)$ & $78(64-85)$ & $78(63-85)$ & $78.5(68-85)$ \\
\hline Heart rate & $82(70-94)$ & $92.5(72-116)$ & $91(71-116)$ & $99(73-116)$ \\
\hline GCS & $15(15-15)$ & $14(3-15)$ & $14(3-15)$ & $14(9-15)$ \\
\hline
\end{tabular}




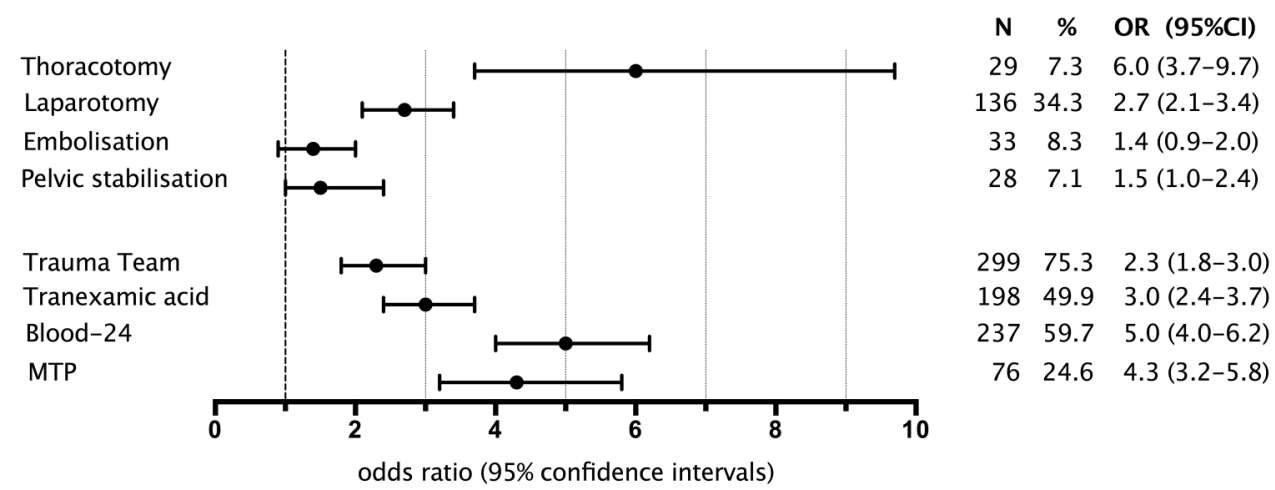

Figure 2 The odds of receiving a trauma intervention for patients with an anatomical indication for resuscitative endovascular balloon occlusion of the aorta and shocked, versus those with an anatomical indication but without evidence of shock. MTP, massive transfusion protocol.

patients per hospital during the study period was substantially higher in MTCs than TUs (7.7 and 0.7, respectively) (table 5).

There was a large range in the number of potential REBOA patients seen at each MTC (between 0 and 34 patients during the study period). We therefore included a further analysis of the 10 MTCs that had the highest incidence of potential REBOA patients-these 10 MTCs saw $40.3 \%$ of the REBOA group patients in the study (table 5). According to these data we would expect, on average, that each MTC would see a patient in whom REBOA may be utilised every 95 days, reducing to 1 every 46 days in the 10 MTCs with the highest presentation of this injury type.

\section{DISCUSSION}

This is the first population based civilian study of trauma patients who had an injury pattern and physiology in which REBOA may have been considered. Our analysis demonstrates that, across England and Wales, a population of 57 million, there were approximately 200 such patients per year. While this number is small, these patients were predominantly young, and their mortality was high (one-third died).

Some of these deaths might have been preventable with more prompt haemorrhage control. More than half of deaths occurred within $12 \mathrm{~h}$ of hospital arrival which, in the absence of unsurvivable TBI (which were excluded), may have been due to incomplete haemostasis. However, patients who died early also had a higher burden of injury (including TBI) compared with survivors, and more profound physiological derangement (39\% had admission physiology consistent with TCA). The potential benefit of REBOA in the clinical setting of TCA is unknown. There is a single published description of successful REBOA resuscitation in a patient with pulseless electrical activity. ${ }^{17}$ However, this patient arrived in the emergency department with an SBP of $60 \mathrm{~mm} \mathrm{Hg}$ and subsequently deteriorated, suggesting a low cardiac output state with a perfusing cardiac rhythm at the time of intervention. In patients without a perfusing cardiac rhythm, REBOA (together with high volume fluid resuscitation) is unlikely to be an effective management strategy. Furthermore, the technical skill required to deploy REBOA in this situation should not be underestimated. Earlier, including prehospital, haemorrhage control is likely to infer a better chance of survival.

The REBOA group, in addition to a high mortality, required considerable trauma resources, both procedural (eg, laparotomy) and logistical (eg, blood transfusion). While the use of REBOA would not reduce the requirement for definitive haemostasis (and indeed might increase it, if more patients are alive to receive it), it is postulated that it could deliver a more haemodynamically stable patient to the proceduralist, and perhaps therefore reduce the total blood transfusion requirements.

A large number of patients in whom REBOA may have been utilised were conveyed to MTCs, and received by a trauma team. The time period of this study includes the date of implementation of the Trauma Network in April 2012, and as such the proportion of REBOA patients currently seen at MTCs is likely to be slightly greater than we have reported. This is encouraging for potential future intervention, as admission to a hospital capable of providing definitive care should optimise outcomes. This should also assist with the adoption of REBOA into clinical practice, as members of the trauma team in an MTC should already have, or could be taught, many of the necessary skills. Previous evaluation of two REBOA training packages suggests that 1-2 days of bespoke training may be adequate for the endovascular interventional novice. ${ }^{21} 22$ The

Table 4 A hospital arrival demographic, physiological and serious traumatic brain injury comparison of REBOA patients; compared as survivors, early deaths $(\leq 12 \mathrm{~h})$ and late deaths $(>12 \mathrm{~h})$

\begin{tabular}{llcc}
\hline & Survivors & Early deaths & Late deaths \\
\hline $\mathrm{n}$ & 270 & 79 & 48 \\
Age (median (IQR)) & $42.1(27.6-59.4)$ & $37.3(25.5-56.7)$ & $57.3(41.8-80.2)$ \\
ISS (median (IQR)) & $25.0(17.0-41.0)$ & $43.0(33.0-50.0)$ & $43.0(29.0-50.0)$ \\
Heart rate (median (IQR)) & $95.0(77.0-116.0)$ & $34.5(0.0-115.0)$ & $101.0(80.0-113.0)$ \\
SBP (median (IQR)) & $80.0(70.0-85.0)$ & $0.0(0.0-77.0)$ & $75.5(63.0-82.0)$ \\
GCS (median (IQR)) & $15.0(14.0-15.0)$ & $3.0(3.0-3.0)$ & $9.5(3.0-15.0)$ \\
AIS 3+ head injury (n (\%)) & $37(13.7)$ & $34(43.0)$ & $21(43.8)$ \\
\hline
\end{tabular}

AIS, Abbreviated Injury Scale; GCS, Glasgow Coma Scale; ISS, Injury Severity Score; REBOA, resuscitative endovascular balloon occlusion of the aorta; SBP, systolic blood pressure. 
Table 5 Type of receiving hospital *

\begin{tabular}{|c|c|c|c|}
\hline Group & TU & MTC & MTC-10 \\
\hline TARN patients (n (\%)) & 46891 (64.5) & $25786(35.5)$ & $12253(16.9)$ \\
\hline No of hospitals in study & 223 & 32 & 10 \\
\hline REBOA patients (n (\%)) & $151(38.0)$ & $246(62.0)$ & $160(40.3)$ \\
\hline Mean REBOA patients/hospital in 2012-2013 & 0.7 & 7.7 & 16.0 \\
\hline Expected interval between REBOA patients/hospital (days) & 1078 & 95 & 46 \\
\hline
\end{tabular}

level of skill to successfully insert a large (currently $12 \mathrm{~F}$ ) arterial access sheath in a profoundly hypovolaemic patient should not be underestimated, although increasing use of ultrasound has helped to reduce the reported median REBOA insertion time to between 4 and 5 min in a porcine model. ${ }^{25}$ While it is likely that this time to REBOA inflation is less than the time to obtain haemostasis in an operating theatre or interventional radiology suite, we are unable to find contemporary data to support this. However, we do not believe that REBOA should be considered in isolation-it is at best a temporary measure to deliver a more stable patient to definitive haemostasis, and in the respect of interventional radiology, an already established arterial access point inferior to the occlusion.

The concentration of REBOA patients in MTCs should also facilitate the much needed further evaluation of this technique for managing haemorrhage. The initial clinical reports of REBOA have given a mixed picture; it is conceptually attractive, and further organised prospective research is required to determine the benefits and harms of the technique against current practice (emergency department thoracotomy, laparotomy, extraperitoneal pelvic packing or any other strategy) without the use of REBOA. However, our study does highlight a potential difficulty with future study design - the small number of patients will make it difficult for any single centre to accumulate sufficient institutional experience to properly evaluate REBOA. Collaboration and innovative study design will therefore be essential.

This study has a number of limitations. The most important is that it is based on a retrospectively applied definition, comprising anatomical injury scores and admission physiological parameters. Anatomical injury scores are not available to clinicians as patients arrive in the emergency department; in reality, decisions are made on the basis of clinical findings, particularly in the context of exsanguinating haemorrhage, and it is not known how well our epidemiological definition would correlate with the clinical decision to use REBOA, or indeed a REBOA clinical practice guideline. Furthermore, the potential harm of REBOA is also unknown, and therefore a comparison with conventional haemostasis techniques (thoracotomy, laparotomy and interventional radiology) without REBOA should be made.

The most important confounder of haemorrhage mortality is TBI, and although we tried to limit the effect of this by excluding the most severe brain injuries, it is impossible to remove altogether. It is intriguing to hypothesise that REBOA, by increasing cerebral perfusion, might assist in mitigating secondary brain injury. However, there are currently no human data to support this concept.

Response to resuscitation is not well recorded in the TARN registry, and it is therefore possible that even those patients who presented in profound hypotension responded to conventional management, thereby not requiring REBOA (although clinical differentiation may be extremely challenging). The net effect of these limitations would be an overestimation of the true number of patients who might have been considered for REBOA. However, the TARN registry is not a complete record of all trauma patients admitted to hospitals in England and Wales. During the period of this study, while all MTCs submitted data to TARN, data submission is not always complete. Furthermore, the use of SBP $90 \mathrm{~mm} \mathrm{Hg}$ as a measure of haemorrhagic shock is questionable. There were 119 patients in this study with an anatomical indication for REBOA who underwent massive transfusion, but who did not present with an SBP $<90 \mathrm{~mm} \mathrm{Hg}$ - the role of REBOA in this group of patients is unknown, and presents potential difficulty in writing clinical practice guidelines.

Outwith REBOA there are other non-conventional strategies that have been shown to improve survival in exsanguinating trauma, including bypassing the emergency department and commencing resuscitation simultaneously to surgical haemostasis in the operating theatre. This technique has further evolved in recent military trauma care and, owing to the geographical layout of the UK military hospital in Afghanistan, has been termed 'right turn resuscitation'. Data from the UK military have demonstrated that while there was no observed difference in survival from right turn resuscitation, there was a significant increase in the number of unexpected survivors. ${ }^{26}$ In addition to REBOA there are a number of other strategies, currently in different stages of development, aimed at managing NCTH, including selective aortic arch perfusion, emergency preservation and resuscitation, abdominal foam and resuscitation with angiography percutaneous treatments and operative resuscitations. Ideally the future utility of REBOA should also be measured against these strategies.

In summary, despite some limitations, this study has succeeded in identifying and characterising a small group of severely injured, resource intensive patients with a highly lethal injury pattern that is theoretically amenable to REBOA. The highest density of these patients is seen at MTCs, and as such a planned evaluation of REBOA should be further considered in these hospitals alongside other conventional and nonconventional management of NCTH.

\section{Author affiliations}

${ }^{1}$ Institute of Naval Medicine, Gosport, Hampshire, UK

${ }^{2}$ Office of the Chief Scientist, 59th Medical Wing, Joint Base San Antonio, United States Air Force, San Antonio, Texas, USA

${ }^{3}$ Academic Department of Military Surgery and Trauma, Royal Centre for Defence Medicine, Birmingham, UK

${ }^{4}$ Academic Unit of Surgery, Glasgow Royal Infirmary, Glasgow, UK

${ }^{5}$ Medical School, University of Campinas, Campinas, Brazil

${ }^{6}$ Department of Anaesthetics, Royal Infirmary of Edinburgh, Edinburgh, UK

${ }^{7}$ Trauma Audit and Research Network, Hope Hospital, Manchester, UK 
${ }^{8}$ EMRiS Group, Health Services Research Section, School of Health and Related Research, University of Sheffield, Sheffield, UK

${ }^{9}$ Departments of Surgery and Intensive Care Medicine, Aberdeen Royal Infirmary, Aberdeen, UK

${ }^{10}$ Health Services Research Unit, University of Aberdeen, Aberdeen, UK

Twitter Follow Antoinette Edwards at @AntoinetteE60

Acknowledgements The authors would like to thank Dr James K Aden, PhD, US Army Institute of Surgical Research, San Antonio, Texas, for initial advice on statistical comparisons.

Contributors The study was conceived by JJM, RL and JOJ. The study permissions were obtained by JJM and JOJ. Data acquisition was undertaken by MF-I, $A E, F L$ and TL. EBGB, JJM, RL, AE, FL, OB, TL and JOJ interpreted the data. The manuscript was prepared by EBGB, JJM, RMM, $A E, O B, T L$ and JOJ. Critical revisions were done by EGB, RL, AE, FL, TL and JOJ. All authors reviewed and approved the final draft.

Competing interests JOJ is in receipt of an NHS Research Scotland (NRS) fellowship, which is an academic salary support scheme funded by the Chief Scientist Office. The Health Services Research Unit receives funding from the Chief Scientist Office of the Scottish Government Health and Social Care Directorates. The opinions expressed in this protocol are those of the authors alone. JJM serves on the clinical advisory board of Pryor Medical Inc (Arvada, CO, USA), which includes travel funding and share options. Pryor Medical Inc is a company involved in the design and manufacturer of REBOA catheters.

Ethics approval TARN has ethical approval (PIAG section 60) for research on the anonymised data that are stored securely on the University of Manchester server.

Provenance and peer review Not commissioned; externally peer reviewed.

Data sharing statement All anonymised data from TARN used for this study have been reported in the manuscript. Applications for additional data can be made in accordance with the TARN data sharing policy (https://www.tarn.ac.uk/).

Open Access This is an Open Access article distributed in accordance with the Creative Commons Attribution Non Commercial (CC BY-NC 4.0) license, which permits others to distribute, remix, adapt, build upon this work non-commercially, and license their derivative works on different terms, provided the original work is properly cited and the use is non-commercial. See: http://creativecommons.org/ licenses/by-nc/4.0/

\section{REFERENCES}

1 National Audit Office. Major trauma care in England. London: The Stationery Office. 2010.

2 Eastridge BJ, Mabry RL, Seguin P, et al. Death on the battlefield (2001-2011): implications for the future of combat casualty care. I Trauma Acute Care Surg 2012;73:5431-7.

3 Singleton JAG, Gibb IE, Hunt NCA, et al. Identifying future "unexpected" survivors: a retrospective cohort study of fatal injury patterns in victims of improvised explosive devices. BMJ Open 2013;3:e003130.

4 Chiara 0, Scott JD, Cimbanassi S, et al. Trauma deaths in an Italian urban area: an audit of pre-hospital and in-hospital trauma care. Injury 2002;33:553-62.

5 Tien HC, Spencer F, Tremblay LN, et al. Preventable deaths from hemorrhage at a level I Canadian trauma center. J Trauma 2007;62:142-6.

6 Teixeira PGR, Inaba K, Hadjizacharia P, et al. Preventable or potentially preventable mortality at a mature trauma center. J Trauma 2007;63:1338-46.
7 Davis JS, Satahoo SS, Butler FK, et al. An analysis of prehospital deaths: Who can we save? J Trauma Acute Care Surg 2014;77:213-18.

8 Morrison JJ, Rasmussen TE. Noncompressible torso hemorrhage: a review with contemporary definitions and management strategies. Surg Clin North $\mathrm{Am}$ 2012;92:843-58.

9 Kisat M, Morrison JJ, Hashmi ZG, et al. Epidemiology and outcomes of non-compressible torso hemorrhage. J Surg Res 2013;184:414-21.

10 Morrison JJ, Stannard A, Rasmussen TE, et al. Injury pattern and mortality of noncompressible torso hemorrhage in UK combat casualties. I Trauma Acute Care Surg 2013;75:S263-8.

11 Avaro J-P, Mardelle V, Roch A, et al. Forty-minute endovascular aortic occlusion increases survival in an experimental model of uncontrolled hemorrhagic shock caused by abdominal trauma. J Trauma 2011;71:720-6.

12 Morrison JJ, Percival TJ, Markov NP, et al. Aortic balloon occlusion is effective in controlling pelvic hemorrhage. J Surg Res 2012;177:341-7.

13 Morrison JJ, Ross JD, Houston R, et al. Use of resuscitative endovascular balloon occlusion of the aorta in a highly lethal model of noncompressible torso hemorrhage. Shock 2014;41:130-7.

14 Scott DJ, Eliason JL, Villamaria C, et al. A novel fluoroscopy-free, resuscitative endovascular aortic balloon occlusion system in a model of hemorrhagic shock. J Trauma Acute Care Surg 2013;75:122-8.

15 Markov NP, Percival TJ, Morrison JJ, et al. Physiologic tolerance of descending thoracic aortic balloon occlusion in a swine model of hemorrhagic shock. Surgery 2013;153:848-56.

16 Martinelli T, Thony F, Decléty $\mathrm{P}$, et al. Intra-aortic balloon occlusion to salvage patients with life-threatening hemorrhagic shocks from pelvic fractures. J Trauma 2010;68:942-8

17 Brenner ML, Moore LJ, DuBose JJ, et al. A clinical series of resuscitative endovascular balloon occlusion of the aorta for hemorrhage control and resuscitation. J Trauma Acute Care Surg 2013;75:506-11.

18 Norii T, Crandall C, Terasaka Y. Survival of severe blunt trauma patients treated with resuscitative endovascular balloon occlusion of the aorta compared with propensity score-adjusted untreated patients. J Trauma Acute Care Surg 2015;78:721-8.

19 Holcomb JB, Fox EE, Scalea TM, et al. Current opinion on catheter-based hemorrhage control in trauma patients. J Trauma Acute Care Surg 2014;76:888-93.

20 Lendrum RA, Perkins ZB, Davies GE. A training package for zone III Resuscitative Endovascular Balloon Occlusion of the Aorta (REBOA). Scand I Trauma Resusc Emerg 2014;22(Suppl 1):18.

21 Villamaria CY, Eliason JL, Napolitano LM, et al. Endovascular Skills for Trauma and Resuscitative Surgery (ESTARS) course: curriculum development, content validation, and program assessment. I Trauma Acute Care Surg 2014;76:929-35.

22 Brenner M, Hoehn M, Pasley J, et al. Basic endovascular skills for trauma course: bridging the gap between endovascular techniques and the acute care surgeon. J Trauma Acute Care Surg 2014;77:286-91.

23 Biffl WL, Fox CJ, Moore EE. The role of REBOA in the control of exsanguinating torso hemorrhage. J Trauma Acute Care Surg 2015;78:1054-8.

24 Morrison JJ, Ross JD, Rasmussen T, et al. Resuscitative endovascular balloon occlusion of the aorta (REBOA): a gap analysis of severely injured UK combat casualties. Shock 2014;41:388-93.

25 Andersen NG, Rehn M, Oropeza-Moe M, et al. Pre-hospital resuscitative endovascular balloon occlusion of the aorta. Scand I Trauma Resusc Emerg Med 2014;22(Suppl 1):19.

26 Tai N, Russell R. Right turn resuscitation: frequently asked questions. J R Army Med Corps 2011;157:S310-14. 